\title{
O uso probiótico no transtorno do espectro autista e na esquizofrenia: revisão narrativa da literatura
}

\author{
Probiotic use in autistic spectrum disorder and schizophrenia: narrative literature \\ review
}

Caio Marcos Ribeiro Gonçalves ${ }^{1}$, Herbert Santana Macedo ${ }^{1}$, Leonardo Novaes Modesto Fernandes ${ }^{1}$, Ivan de Sousa Araújo ${ }^{2,3,4}$, Roberto Paulo Correia de Araujo5 , Jozélio Freire de Carvalho ${ }^{6 *}$

\begin{abstract}
${ }^{1}$ Graduando em Medicina pela Universidade Salvador (UNIFACS); ${ }^{2}$ Professor Titular de Psiquiatria do curso de Medicina da Universidade Salvador; ${ }^{3}$ Preceptor do Programa de Residência Médica de Psiquiatria Infantil do Hospital Juliano Moreira; ${ }^{4}$ Preceptor do Programa de Residência Médica de Pediatria do Hospital Geral Roberto Santos. ${ }^{5}$ Professor Titular de Bioquímica, Programa de Pós-graduação Processos Interativos dos Órgãos e Sistemas da UFBA; ${ }^{6}$ Professor Visitante do Programa de Pós-graduação Processos Interativos dos Órgãos e Sistemas do ICS/UFBA
\end{abstract}

\begin{abstract}
Resumo
Introdução: devido à grande prevalência do transtorno do espectro autista (TEA) e da esquizofrenia e o caráter incapacitante dessas patologias, fez-se necessário o desenvolvimento de tratamentos cada vez mais eficientes e com menos efeitos adversos. Sendo a microbiota um regulador da inflamação e tendo esta um papel fundamental na gênese dos transtornos psiquiátricos, o uso de probióticos pode ser uma alternativa segura e com baixo custo para o tratamento complementar das doenças psiquiátricas. Objetivo: realizar uma revisão narrativa sobre a eficácia do uso de probióticos na redução de sintomas clínicos e gastrointestinais, assim como da segurança no tratamento do TEA e da esquizofrenia. Metodologia: revisão dos estudos em humanos que avaliaram os efeitos terapêuticos dos probióticos no TEA e esquizofrenia. Resultados: foram selecionados 13 estudos, sendo 8 sobre TEA e 5 sobre esquizofrenia, com total de 485 pacientes. As evidências apontam melhora dos sintomas gastrintestinais dos pacientes com TEA e esquizofrenia; entretanto, sem mudanças conclusivas dos sintomas psiquiátricos na esquizofrenia, associado a potencial benefício no TEA. Conclusão: essa revisão sugere que o uso de probióticos tem um potencial benefício nos sintomas comportamentais no TEA, associado à melhora dos sintomas gastrointestinais na esquizofrenia e TEA; entretanto, não se observou mudanças nos sintomas psiquiátricos da esquizofrenia.
\end{abstract}

Palavras-chave: Probiótico. Psicobiótico. Transtorno do Espectro Autista. Esquizofrenia.

\begin{abstract}
Introduction: due to the high prevalence of autism spectrum disorder (ASD) and schizophrenia and the disabling nature of these pathologies, it has become necessary to develop increasingly efficient treatments with less adverse effects. As the microbiota is a regulator of inflammation and having a fundamental role in the genesis of psychiatric disorders, the use of probiotics may be a safe and low-cost alternative for the complementary treatment of psychiatric diseases. Objective: to perform a narrative review on the efficacy of probiotics use in reducing clinical and gastrointestinal symptoms, and adverse effects of the use of probiotics in the treatment of ASD and schizophrenia. Methodology: review of studies in humans that evaluated the therapeutic effects of probiotics on ASD and schizophrenia. Results: 13 studies were selected, 8 on TEA and 5 on schizophrenia, with a total of 485 patients. Evidence points to improvement in gastrointestinal symptoms in patients with ASD and schizophrenia; however, there were no conclusive changes in psychiatric symptoms in schizophrenia, associated with a potential benefit in ASD. Conclusion: This review suggests that the use of probiotics has a potential benefit in behavioral symptoms in ASD, associated with the improvement of gastrointestinal symptoms in schizophrenia and ASD; however, there were no changes in the psychiatric symptoms of schizophrenia.

Keywords: Probiotic; Psychobiotic; Autistic Spectrum Disorder; Schizophrenia.
\end{abstract}

\section{INTRODUÇÃO}

O conceito de microbiota pode ser resumido como o conjunto de microrganismos que residem no corpo humano. A microbiota humana possui aproximadamente 9 milhões de genes, o que corresponde a 450 vezes mais do que o genoma humano. A microbiota é encontrada

Correspondente/Corresponding: *Jozélio Freire de Carvalho - End: Rua das Violetas, 42, ap. 502, Pituba Salvador, BA CEP: 41810-080 - Tel: 55 (71) 99187-1169-E-mail: jotafc@gmail.com nas cavidades oral e vaginal, na pele, nas vias aéreas e no trato gastrointestinal(YANG et al., 2009).

A microbiota possui uma relação de desenvolvimento que acontece de forma bidirecional com o sistema imune. É sabido que a microbiota é capaz de induzir ativação gênica nos cólons, sendo que metade desses genes estão associados ao sistema imune(MARQUES; MACKAY; KAYE, 2017). De forma análoga, a microbiota possui uma comunicação recíproca com o sistema nervoso central, denominado de eixo cérebro-intestino (gut-brain axis) 
(FOSTER; MCVEY NEUFELD, 2013). Essa comunicação acontece através da modulação do sistema imune, da produção de ácidos graxos de cadeia curta (AGCC), produção de neurotransmissores e a estimulação do nervo vago(KENNEDY et al., 2017). Corroborando com isso, foi observado que ratos sem microbiota (germ-free) possuem alteração no comportamento social, na resposta ao stress, ansiedade, memória e função cognitiva (NEUFELD et al., 2011). Diversos fatores influenciam no processo dinâmico de maturação da microbiota, dentre eles, o modo de nascimento, a forma de amamentação, a utilização de antibióticos, o local de criação (urbano x rural) e a genética. Estes são alguns dos fatores que contribuem, em especial nos primeiros 1000 dias, para maturação do sistema neuroimunológico (VERDU; GALIPEAU; JABRI, 2015). Dentre os processos cerebrais que sofrem influência da microbiota estão o comportamento, o metabolismo de serotonina, a regulação da integridade da barreira hematoencefálica e a regulação do apetite(SCHROEDER; BÄCKHED, 2016).

\section{MICROBIOTA E INFLAMAÇÃO}

Um dos principais processos metabólicos que são modulados pela microbiota é a inflamação. Isso acontece através do equilíbrio entre bactérias simbiôntica e patobiônticas (KOBOZIEV et al., 2014). O principal fator regulador é a dieta, em especial, a quantidade disponível de polissacarídeos fermentáveis na luz intestinal. Estes açúcares sofrem um processo de fermentação, produzindo os AGCC. Existem três tipos principais de AGCC: butirato, propianato e acetato (BRANDSMA et al., 2015). Tais elementos agem por duas vias principais, seja através da regulação das histonas desacetilases ou ligando-se aos receptores da proteína G (GPR). O butirato tem maior potencial anti-inflamatório, através de diminuição de citocinas pró inflamatórias, a exemplo do fator de necrose tumoral (TNF), fator de transcrição nuclear kappa b (NFkB), interleucina 1 beta (IL-1b) e um aumento de fatores anti-inflamatórios como a interleucina 10 (IL-10)(TAN et al., 2014). Além da produção de AGCC, a manutenção da integridade da barreira intestinal se tona um fator fundamental no controle da translocação de bactérias para a corrente sanguínea. $O$ epitélio intestinal se protege da agressão bacteriana através da produção do muco, o qual é composto de mucinas e agentes antibacterianos, a exemplo da defensina e imunoglobulina $\mathrm{A}$ (JOHANSSON; HANSSON, 2016). Em ratos sem microbiota é observado um aumento da permeabilidade intestinal através da diminuição das junções de oclusões (claudina e ocludina). Dessa forma, as bactérias gram-negativas, as quais possuem moléculas de lipopolissacarídeo (LPS), translocam-se para a corrente sanguínea. Através da ligação do LPS com os receptores do tipo toll 4 (TLR4), é iniciado um processo inflamatório através da indução do NFkB, gerando citocinas inflamatórias(CABALLERO; PAMER, 2015).

\section{TRANSTORNO DO ESPECTRO AUTISTA (TEA)}

O Transtorno do Espectro Autista (TEA) é uma perturbação crônica do neurodesenvolvimento, que afeta uma em cada 64 crianças no mundo (BARON-COHEN et al., 2009), se manifesta precocemente e tem como manifestações clínicas alterações nos campos de: (a) interação social, (b) comunicação verbal e não verbal, (c) interesses restritos e comportamentos repetitivos e estereotipados (BARON-COHEN, 2004).

Foi observado que pacientes autistas possuem níveis elevados de propianato, o qual tem efeitos benéficos, todavia, em altas quantidades produz alterações de comportamento (MACFABE, 2012). Os AGCC cruzam a barreira hemato-encefálica, sendo absorvida pela glia e pelos neurônios, em menor extensão. Eles aumentam a síntese de dopamina e induz tirosina didroxilase, enzima fundamental na síntese de catecolaminas. O mecanismo parece estar associado com uma absorção excessiva de AGCC. A injeção de propianato em ratos altera os níveis de dopamina, serotonina e glutamato, levando a comportamentos semelhantes à TEA (NGUYEN et al., 2018). Aliado a isso, há a evidência de que pacientes com TEA possuem altos níveis de Clostridial e Bacteriodestes especies, as quais são produtoras eficientes de propianato. Conjuntamente é observado um aumento nos níveis de citocinas e diminuição de TGF- $\beta$ associado com ativação da micróglia e astroglia(LYTE; CRYAN, 2014).

Além da observação na mudança das concentrações de AGCC, $90 \%$ dos pacientes com TEA possuem comorbidades gastrintestinais; a exemplo de constipação, diarreia, dor abdominal e vômito. A extensão das disfunções gastrointestinais pode predizer a severidade dos comportamentos autistas (SHERWIN et al., 2016).

\section{ESQUIZOFRENIA}

Esquizofrenia é uma doença multifatorial, a qual sofre influência de diversos fatores, incluindo genético e ambiental, os quais interagem entre si (MAQSOOD; STONE, 2016). Isso reflete em uma fisiopatologia complexa e heterogênea. Segundo a revisão sistemática de Saha et al, a prevalência da esquizofrenia é de 3,3 para cada 1000 pessoas(SAHA et al., 2005). Estudos têm sugerido que processos que causam interferência no neurodesenvolvimento podem resultar em um maior risco de psicose (WATKINS; ANDREWS, 2016). Infecção intra-útero tem sido apontado como um período crítico de vulnerabilidade, em especial, devido à maturação do sistema neuroimune(KANJl et al., 2017).

Algumas revisões tem sugerido que a neuroinflamação faz parte do processo central da fisiopatologia da esquizofrenia (KANJI et al., 2017; KARAKUŁA-JUCHNOWICZ et al., 2016; NEMANI et al., 2015). Isso é corroborado com a evidência de que pacientes com esquizofrenia possuem um aumento de IL- 6 e uma diminuição de IL-10, caracterizando assim um status inflamatório (MAQSOOD; STONE, 2016). Associado a isso há também 
uma diminuição da funcionalidade do fator neurotrófico derivado do cérebro (BDNF)(NEMANI et al., 2015), uma proteína responsável pela sobrevivência e diferenciação dos neurônios, neuroplasticidade e funcionalidade das sinapses (LYTE; CRYAN, 2014). Em ratos sem microbiota foi observado uma diminuição nos níveis de BDNF e nos receptores $\mathrm{N}$-metil D-Aspartato (NMDAR), um receptor do tipo glutamatérgico. Antagonistas do receptor NMDA produzem comportamentos do tipo esquizofrênico (NEMANI et al., 2015). O ácido quinolínico e ácido quinurênico, metabólitos do triptofano, são agonista e antagonista, respectivamente, do NMDAR, receptor responsável pela produção de BDNF(MAQSOOD; STONE, 2016). Associado a isso, sabe-se que Bifidobacterium infantis, lactobacillus plantarum e L. lactis, produzem serotonina e que ratos normais possuem três vezes mais serotonina no plasma comparado aos ratos sem microbiota, de forma que a microbiota é um regulador central do metabolismo de serotonina/triptofano(O'MAHONY et al., 2015). A inflamação aumenta os níveis da enzima indolamina 2,3-dioxigenase (IDO), a qual desvia o metabolismo do triptofano para a produção de ácido quiniolínico e ácido quinurênico (KENNEDY et al., 2017).

\section{PROBIÓTICOS}

Probióticos são suplementos alimentares compostos por microrganismos vivos que tem como finalidade a restauração do equilíbrio da composição da microbiota intestinal, a fim de promover efeitos benéficos ao hospedeiro. Os gêneros mais utilizados nas formulações de probióticos são Lactobacillus e Bifidobacterium (LYTE; CRYAN, 2014).

Algumas bactérias como lactobacilli, produzem ácido gama-aminobutírico (GABA) a partir do L-glutamato, como forma de proteção ao pH ácido. Essa produção de GABA também serve como um mecanismo de comunicação com as células neuronais do intestino e as células imunes. 0 GABA exerce uma ação anti-inflamatória através da inibição tanto do NFkB como da resposta da micróglia ao LPS. IL-1 $\beta$ bloqueia o sinal do GABA. A administração de L. rhamnosus em ratos provocou a mudança nos níveis de GABA em regiões associadas com comportamento específicos, que resultou na diminuição de comportamento ansioso e depressivo. Além de GABA, bactérias do filo Bacillus e Serrata produzem dopamina. Ratos germ-free possuem baixos níveis de dopamina no lúmen. Após inoculação com bactérias que possuem beta-glucoronidase, notou-se uma elevação nos níveis de dopamina (MAQSOOD; STONE, 2016).

Cerca de 95\% do 5-HT do corpo está localizado dentro do trato $\mathrm{Gl}$, principalmente sintetizado por células. Ratos normais possuem 3 vezes mais serotonina no plasma comparado com ratos germ-free, sendo que o nível de Triptofano é $40 \%$ menor nos normais. Os níveis de serotonina no córtex e no hipocampo foram significativamente reduzidos em ratos germ-free. Bifidobacterium infantis, lactobacillus plantarum e L. lactis, produzem serotonina (O'MAHONY et al., 2015).

Os medicamentos utilizados no tratamento das doenças psiquiátricas têm como via de ação a modulação dos neurotransmissores. Devido ao seu relativo sucesso terapêutico, tem-se inferido que a quebra da homeostase dos neurotransmissores participa do processo de formação e manutenção dos transtornos psiquiátricos. Assim, baseado nas evidências que a microbiota participa da produção de neurotransmissores e da sua eficácia dos estudos em animais, levanta-se a hipótese de que o uso de probióticos pode ser benéfico como uma alternativa de baixo custo no tratamento de doenças psiquiátricas.

O objetivo desse estudo foi realizar uma extensa revisão do uso de probióticos no trantorno do espectro autista e na esquizofrenia.

\section{METODOLOGIA}

\section{DESENHO DE ESTUDO}

\section{Revisão Sistemática Qualitativa.}

Para o levantamento dos artigos na literatura, realizou-se uma busca nas bases de dados da US National Library of Medicine (Pubmed). Foram utilizados, para busca dos artigos, os seguintes descritores e suas combinações em língua inglesa: schizophrenia; autism; probiotic.

\section{CRITÉRIOS DE INCLUSÃO}

Foram considerados elegíveis para inclusão na revisão estudos originais realizados em humanos, publicados em inglês ou português até julho de 2020, sem limitação para data inicial de publicação, que relacionassem o uso de probióticos e em pessoas diagnosticadas com Transtorno do Espectro Autista ou Esquizofrenia.

\section{CRITÉRIOS DE EXCLUSÃO}

Foram excluídos, na análise qualitativa dos artigos, estudos referentes artigos não-originais (editoriais, comentários, revisões, capítulos de livros e cartas), estudos realizados em animais ou in vitro.

\section{COLETA DE DADOS}

Os artigos identificados foram avaliados de forma independente por dois pesquisadores. As discordâncias quanto à inclusão/exclusão foram resolvidas por um terceiro investigador. A primeira fase da seleção foi caracterizada pela análise dos títulos e, a posteriori, foi realizado a análise dos resumos. Por último, foi feito a leitura integral dos estudos para verificar os critérios de elegibilidade.

\section{ASPÉCTOS ÉTICOS}

Haja vista que esse trabalho se trata de uma pesquisa observacional, do tipo revisão sistemática de estudos já publicados na literatura, dispensou-se a submissão comitê 
de ética em pesquisa em seres humanos, dado que os dados utilizados são secundários e já foram divulgados. A pesquisa foi conduzida observando a Resolução 466/12 CONEP-CNS/MS.

Os resultados da pesquisa serão divulgados em eventos e periódicos científicos. A pesquisa possibilitará a ampliação do conhecimento do tema estudado, podendo impactar na saúde e qualidade de vida dos pacientes com transtorno do espectro autista e esquizofrenia.

\section{RESULTADOS}

A busca na base de dados do Pubmed obteve como resultado um total de 199 artigos. Desses, após a aplicação dos critérios de elegibilidade, 13 foram selecionados para inclusão na revisão, sendo 8 artigos em crianças com TEA e 5 artigos em adultos com esquizofrenia. $O$ fluxograma com a seleção de artigos é apresentado na Figura 1.

Figura 1 - Fluxograma de seleção dos artigos.

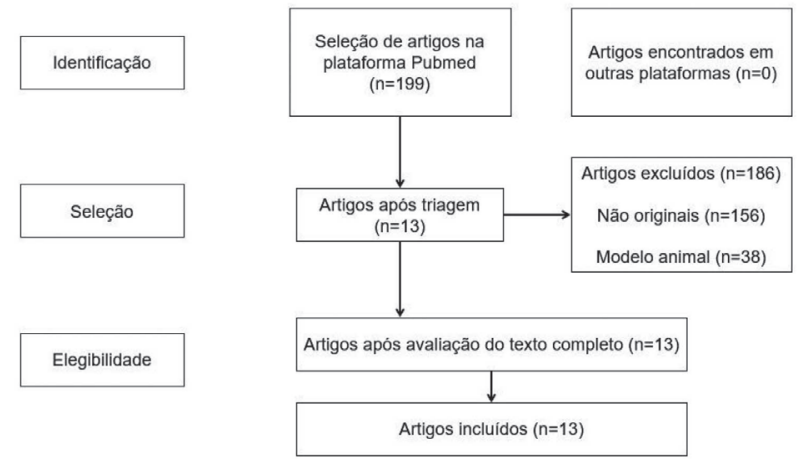

Fonte: Autoria própria

\section{ESQUIZOFRENIA}

Foram encontrados 5 artigos sobre o uso de probióticos em adultos com esquizofrenia. Desses, três publicações são referentes à mesma pesquisa(DICKERSON et al., 2014; SEVERANCE et al., 2017; TOMASIK et al., 2015). $O$ estudo em questão foi realizado nos Estados Unidos, com o método duplo cego, randomizado e com controle placebo com uma duração de 14 semanas com 58 pessoas entre 18 e 65 anos. A intervenção foi com a utilização das cepas $10^{9}$ Lactobacillus rhamnosus strain GG e $10^{9}$ Bifidobacterium animalis subsp. lactis $B b 12$. Os resultados encontrados são sintetizados na Tabela 1.

Inicialmente, foram selecionados 65 pacientes para o estudo, todavia apenas 58 mantiveram-se até o fim do tratamento. Os pacientes são provenientes do programa de reabilitação psiquiátrica em Baltimore, os quais, no momento da inscrição, estavam tendo acompanhamento ambulatorial. $\mathrm{O}$ diagnóstico de esquizofrenia foi realizado conforme os parâmetros do DSM-IV, incluindo as desordens esquizoafetivas.

Os critérios de inclusão abrangiam a idade entre 18 a 65 anos; sintomas psicóticos residuais na categoria "moderado severo" ou maior, conforme o escore PANSS - Positive and Negative Syndrome Scale - com sintomas positivos $=1 \mathrm{e} / \mathrm{ou}$ sintomas negativos $=4$ ou um escore total $=50$, com pelo menos 3 itens positivos ou negativos; Os pacientes deveriam estar usando sua medicação psicótica por pelo menos 8 semanas antes do início do estudo, sem nenhuma alteração nos últimos 21 dias.

Foram excluídas pessoas com diagnóstico prévio de doença celíaca ou retardo mental; qualquer instabilidade clínica ou medicamentosa (incluindo doenças hepáticas, falência renal ou insuficiência coronariana congestiva); imunodeficiências prévias; uso de antibiótico nos últimos 14 dias.

O estudo foi precedido de 2 semanas do uso de placebo por todos os participantes. Eles eram monitorados semanalmente, para relatar a função gastrointestinal (através de uma escala de 4 pontos sobre o esforço ao defecar) e possível efeitos adversos, assim como garantir a aderência ao tratamento. A cada 2 semanas os pacientes preenchiam a escala PANSS. Os pacientes também eram perguntados sobre eventos diarreicos e uso de laxantes.

Na primeira publicação do grupo, em 2014, Dickerson et al.(DICKERSON et al., 2014) demonstraram através do desfecho primário que não houve diferença significativa entre os grupos no uso de laxantes e eventos diarreicos, assim como não houve interação entre os grupos e a pontuação na escala PANSS. Todavia, no desfecho secundário, observou-se que o grupo com uso de probiótico teve menor relato de dificuldade severa na evacuação (hazard ratio $=0.23 ; 95 \% \mathrm{Cl}, 0.09-0.61 ; \mathrm{P}=0.003)$.

Em sua segunda publicação, feita por Tomasik et al.(TOMASIK et al., 2015), foi analisado 47 marcadores imunes, sendo que, apenas 27 satisfizeram os critérios de análise. Foi observado uma redução significativa $(P=$ 0.05 ) nos níveis de Fator von Willebrand (VWF), com uma diferença de $11 \%$. Conjuntamente, houve um aumento com significância borderline $(P=0.08)$ de proteína de quimioatração de monócitos (MCP1), Fator Neurotrófico Derivado do Cérebro (BDNF), quimiocina CCL5 (RANTES), proteína inflamatória de macrófagos-1 beta (MIP-1ß) CCL4).

Na terceira publicação do grupo, Severance et al. 2017, buscaram analisar a associação entre os níveis de Candida albicans e Saccharomyces cerevisiae com mudanças na função do trato gastrointestinal e a manifestação dos sintomas associados à esquizofrenia, através da escala de PANSS.

Não houve diferença nos níveis de Anti-Saccharomyces cerevisiae IgG anticorpo (ASCA) entre os grupos, por isso, a análise concentrou-se, nos níveis de Anti- $C$. albicans. Nos homens, os níveis de IgG Anti-C. albicans foram significativamente reduzidos comparado ao placebo $(p<0.001)$. Houve um indivíduo com níveis iniciais muito altos o qual também houve um grande decréscimo. Para não haver influência em relação ao grupo, foi feito a análise com a sua retirada da amostra. Mesmo assim a redução se manteve significativa $(p<0.0002)$. 
18.2\% dos indivíduos do grupo masculino que recebeu probiótico não houve diminuição nos níveis de IgG com o tratamento, comparado com $44 \%$ do grupo placebo.

Foi observado também que, os níveis de IgG foram consistentemente elevados nos pacientes com condições patológicas no trato gastrointestinal comparado àqueles que não possuíam. Comparando os homens soropositivos para C. Albicans IgG com os soronegativos, foi observado que, no grupo placebo o escore de dificuldade de evacuação era maior nos soropositivos $(n=5)$ comparado aos soronegativos $(n=10)$. Todavia, no grupo em uso de probiótico, não houve diferenças significativas. Os homens que eram soropositivos tinham níveis significativamente elevados no escore PANSS total comparado aos soronegativos.

Okubo et al. em 2018, avaliaram os efeitos do tratamento com Bifidobacterium breve A-1 nos sintomas ansiosos e depressivos em pacientes com esquizofrenia. O estudo reuniu 29 pacientes diagnosticados com esquizofrenia, com mais de 20 anos de idade, que apresentavam sintomas ansiosos e depressivos equivalentes a uma pontuação $\geq 10$ no Brief Psychiatric Rating Scale (BPRS). Além dos sintomas, foram avaliados os hábitos alimentares dos pacientes através da aplicação do Food Frequency Questionnaire antes do início da intervenção.

Os pacientes consumiram 02 sachês/dia contendo $2 \mathrm{~g}$ B. breve $A-1$, a $10^{11} \mathrm{ufc} / \mathrm{dia}$ por 04 semanas. Os sintomas ansiosos e depressivos foram avaliados através da aplicação do escores Hospital Anxiety and Depression Scale (HADS) e Positive and Negative Syndrome Scale (PANSS) no 1a dia e ao final da 4a e 8a semanas. Em relação ao PANSS, foram considerados os itens 1, 2, 3, 4 e 6 de um total de 30 itens, sendo estes relacionados aos sintomas ansiosos ou depressivos. Foram coletadas amostras de sangue no 1a dia e na 4a semana; amostras de fezes no 1a dia, 4a e $8^{\mathrm{a}}$ semana. Ao final do estudo, os pacientes foram separados em dois grupos; aqueles que apresentaram redução do HADS $\geq 25 \%$, foram classificados como "responsivos", o restante, como "arresponsivos".

Comparado ao 10 dia, houve uma redução significativa no escore HADS na 4 a semana $(p=0.037)$ em contraste com a 8 a semana, onde não foi notada uma melhora significativa $(p=0.295)$. Em relação ao PANSS, houve uma redução significativa em ambas 4 a $(p=0.004)$ e $8^{a}$ $(p=0.003)$ semanas.

Em relação aos hábitos alimentares, foi notado que os "responsivos" consumiam, em sua dieta usual, uma quantidade significativamente menor de laticínios do que os "arresponsivos" (252g/dia vs. 663g/dia, respectivamente. $p<0.05$ ).

Ao comparar a dosagem do antipsicótico em uso, sintomas de esquizofrenia, escores HADS e PANNS entre os dois grupos, os "responsivos" apresentaram menos sintomas negativos ( 10.3 vs. $11.8, p<0.05$ ).

Quanto aos gêneros das bactérias encontradas, o grupo "responsivos" apresentou maiores níveis de Parabacteroides $(p=0.026)$ e menores níveis de Bifidobacterium $(p=0.106)$ no 1 ㅇ dia em relação aos "arresponsivos". Não houve mudanças significativas dos níveis de Bifidobacterium na 4a e 8a semana em ambos grupos.

Dentre as 34 citocinas avaliadas no 1 을 dia e ao final da 4a semana, houve um aumento significativo de IL-22 $(p=0.002)$ e TRANCE ( $p=0.006)$ no grupo de "responsivos". Não houve alterações significativas de citocinas no grupo de "arresponsivos".

Mais recentemente, em 2019 Ghaderi et al. conduziram um ensaio clínico randomizado duplo-cego que avaliou os efeitos da suplementação de Vitamina $D$ associado ao uso de probióticos por 12 semanas em 60 pacientes diagnosticados com Esquizofrenia. Os participantes foram divididos entre um grupo placebo e um grupo teste. Foi utilizado Vitamina D3 na dose de 50,000 UI a cada 2 semanas e probióticos na dose $8 \times 10^{9}$ UFC por dia contendo Lactobacillus acidophilus, Bifidobacterium bifidum, Lactobacillus reuteri e Lactobacillus fermentum. Foram avaliados parâmetros clínicos a partir dos escores PANSS e BPRS e parâmetros bioquímicos, a exemplo da Capacidade Antioxidante Total. Os resultados mostraram melhora clínica a partir dos escores PANSS total $(P=0.01)$, nas subescalas PANSS geral $(P=0.004)$ e PANSS negativo $(P=0.03)$, e BPRS $(P=0.03)$.

\section{AUTISMO}

Dos 8 artigos feitos com pacientes com TEA, 2 eram do tipo estudo de coorte, 1 estudo transversal e 1 estudo de caso. Todos foram escritos no idioma inglês. Os anos de publicação dos artigos variaram de 2012 a 2019. O número amostral variou de 1 (estudo de caso) a 71 participantes. Os resultados encontrados são sintetizados na Tabela 2.

A primeira pesquisa que buscou avaliar o impacto do uso de probiótico em crianças com TEA foi realizado na Polonia por Kaluzna-Czaplinska e Sylwia Blasczyk em 2012. O diagnóstico foi realizado conforme os critérios da Diagnostic and Statistical Manual of Mental Disorders. Foram selecionadas 22 crianças (2 meninas e 20 meninos) com TEA, com idade de 4 a 10 anos, as quais participavam do centro de reabilitação em Lodz. A dieta das crianças era livre de açúcar e nenhuma delas havia recebido terapia com antibiótico no período próximo ao início da intervenção. Todas elas tendiam a sofrer de sintomas gastrointestinais. As crianças não sofriam de disfunção renal. Como intervenção foi utilizado a suplementação de Lactobacillus acidophilus $\left(5 \times 10^{9}\right.$ UFC/g) duas vezes ao dia por 2 meses. Foram coletavas amostrar de urinas todas as noites durante o período da suplementação.

Comparado ao período pré-suplementação, houve um decréscimo significativo dos níveis de $D$-Arabinitol $(p<0.05)$. De igual forma a relação D-Arabinitol/L-Arabinitol (DA/LA) também reduziu. Foi observado também uma melhora na habilidade de concentração e seguir ordens. As habilidades de contato com os olhos e reação à emoção de outras pessoas não apresentou melhora. 


\section{ARTIGO 2}

Shaaban et al. publicou em 2017 um estudo realizado no Egito com 30 crianças com TEA, diagnosticadas conformo os critérios do Diagnostic and Statistical Manual of Mental Disorders. Das 30 crianças, 11 eram do sexo feminino e 19 do sexo masculino com idades entre 5 a 9 anos. Todas as crianças no estudo sofreram intervenção do uso de probióticos. Foram utilizadas três cepas bacterianas, sendo estas Lactobacillus Acidophilus, Lactobacillus Rhamnosus e Bifidobacteria Longun. A dose diária utilizada no tratamento consistia em 5 gramas de um mix probiótico de $5 \mathrm{~g}$ sendo que cada grama continha $100 \times 10^{6}$ de células bacterianas liofilizadas. Essa dosagem diária foi utilizada for 3 meses. Para a mensuração da severidade dos sintomas foi utilizado a escala Autism Treatment Evaluation Checklist (ATEC) e para a avaliação dos sintomas gastrintestinais foi utilizado uma versão modificada do GI Severity Index (6-GSI). Foi observado uma redução importante de grande parte dos índices do ATEC score. O valor total do ATEC score diminuiu significativamente com o uso da terapia de probióticos nas crianças autistas, indicando redução na severidade dos sintomas da TEA $(p=0.0001)$.

\section{ARTIGO 3}

Em 2014, Tomova et al. realizaram um estudo na Eslováquia do tipo coorte, no qual foram selecionadas 29 crianças, das quais 10 crianças diagnosticadas com TEA sofreram a intervenção, enquanto 19 crianças foram utilizadas como controle, sendo 9 irmãos sem TEA e 10 crianças sem TEA. As crianças com TEA foram selecionadas a partir do Autism Center em Bratislava. Foi realizado a suplementação de uma capsula do probiótico "Children Dophilus" que contém 3 cepas de Lactobacillus (60\%), duas cepas de Bifidobacterium (25\%) e uma cepa de Streptococcus (15\%) a qual foi administrada por via oral três vezes ao dia por 4 meses. A avaliação psicológica das crianças com TEA foi mensurada utilizando a escala CARS (Childhood Autism Rating Scale), desenvolvida para a identificação e diagnóstico diferencial de crianças com autismo. Também foi utilizada a uma versão ajustada da ADI (Autism Diagnostic Interview), uma entrevista semiestruturada para os pais dos pacientes que respondem questões a respeito do comportamento do paciente. A pesquisa correspondia à busca de 35 itens em 4 áreas: interação social, comunicação, fala e comportamento restrito e repetitivo, classificados numa escala de 3,4 ou 5 pontos. A condição gastrointestinal foi avaliada com base em questionários aplicados aos pais, sendo que a ausência do sintoma significava 0 , e a presença do sintoma era quantificada de 1 a 4 dependendo da severidade do sintoma. Os níveis de citocina foram medidos nos sobrenadantes das fezes, usando ELISA sensível para TNF- $\alpha$.

$O$ estudo encontrou também forte correlação entre os níveis de TNFa e os sintomas gastrointestinais ( $R=$ $0.78, p<0.05$ ). Além disso, os dados mostraram que há uma correlação entre o TNF $\alpha$ nas fezes e a severidade do autismo. A suplementação com probióticos diminuiu significantemente os níveis de TNFa nas fezes das crianças com TEA ( $p<0.05)$. Também foi observado que a relação entre Bacteroidetes/Firmicutes foi significantemente menor nos autistas comparado com os controles. Conjuntamente houve um aumento absoluto na quantidade de Lactobacillus e diminuição dos níveis de Desulfovibrio. Foi visto também que, as crianças com TEA severo (CARS >= 50) tiveram maiores quantidades de Clostridia e Desulfovibrio e menores quantidades da relação Bacteroidetes/ Firmicutes comparado as crianças com TEA suave.

\section{ARTIGO 4}

Grossi et al. publicaram em 2016, um relato de caso de um garoto de 12 anos com TEA e severa perda cognitiva que era acompanhado no Instituto Villa Santa Maria desde 2009. Foi utilizado o tratamento com o probiótico VSL\#3, contendo $9 \times 10^{10}$ bifidobacteria liofilizada (Bifidobacterium breve, $B$. longum, $B$. infantis), $8 \times 10^{10}$ lactobacilli (Lactobacillus acidophilus, L. plantarum, L. paracasei, L. bulgaricus, L. delbrueckii subsp.) e $20 \times 10^{10}$ Streptococci (S. thermophilus, S. salivarius subsp.). A intervenção foi feita por 4 semanas e após isso foi feito um acompanhamento de 4 meses. Para o diagnóstico de TEA foi utilizada os critérios da ADOS-2. O escore utilizado para diagnóstico e acompanhamento foi o ADOS-2 (Escala de Observação para o Diagnóstico de Autismo 2), que tem por finalidade analisar comportamentos em dois domínios distintos. $\mathrm{O}$ primeiro domínio analisa o Relacionamento Social (RS) e o outro, os Movimentos e Comportamentos Repetitivos (MCR). Apesar não ter havido mudança no domínio $M C R$, houve uma redução de 2 pontos no domínio RS, o qual seguido de uma queda de mais 1 ponto durante o acompanhamento, indo de 20 para 17 pontos. Houve também uma melhora da severidade dos sintomas gastrointestinais.

\section{ARTIGO 5}

Sanctuary et al. 2019, conduziram um estudo duplo-cego, randomizado, publicado em 2019 que buscou avaliar os efeitos de uma suplementação com produto de colostro bovino (BCP) e Bifidobacterium infantis em crianças diagnosticadas com TEA e com sintomas gastrointestinais. 0 estudo reuniu 08 crianças, de 02-11 anos de idade, diagnosticadas com TEA segundo o Autism Diagnostic Observation Schedule (ADOS), que apresentavam constipação funcional, diarreia funcional e/ou síndrome do intestino irritável diagnosticadas mediante o Pediatric Gastrointestinal Symptoms-Rome III Version (QPGS-RIII). Os participantes receberam dois tipos de tratamento, um composto por $0.15 \mathrm{~g} / \mathrm{lb} / \mathrm{dia}$ de BCP e o outro composto por BCP $+2.10^{10} \mathrm{ufc} /$ dia de Bifidobacterium infantis. Nas primeiras 05 semanas era instituído, aleatoriamente, um dos tratamentos, seguidos de um período de 02 semanas sem tratamento, finalizando com mais 05 semanas de uso do tratamento restante. Todos os pacientes receberam 
ambos tratamentos e fizeram visitas onde foram coletadas amostras de sangue, urina e fezes, além da aplicação dos questionários de comportamento $\mathrm{ABC}$ (Aberrant Behavior Checklist), RBS-R (Repetitive Behavior Scale-Revised) e ABAS-II (Adaptive Behavior Assessment System-Second Edition) e dos questionários de sintomas gastrointestinais QPGS-RIII e GIH (Gastrointestinal History).

Houve apenas um desfecho relevante em relação à ordem dos tratamentos: em relação ao escore GIH e aos sintomas diarreicos, os pacientes que receberam o BCP primeiro apresentaram um aumento médio do escore = 0.25 ( $p=0.005)$, enquanto aqueles que receberam a combinação primeiro apresentaram uma diminuição média do escore $=-1.25(p=0.005)$.

Ao final das 12 semanas, foi notado uma melhora significativa dos sintomas gastrointestinais enquanto no tratamento com BCP $(n=7)$ e na combinação $(n=8)$. Em relação ao tratamento com $B C P$, houve uma redução na frequência de diarreia $(p=0.021)$ e da dor ao defecar $(p=0.044)$, além de melhora da consistência das fezes $(p=0.042)$. Com o tratamento combinado, foram notadas, também, uma redução na frequência da dor ao defecar $(p=0.02)$ e uma melhora na consistência das fezes $(p=0.015)$. Além disso, os pais dos participantes relataram um aumento geral no apetite e no consumo de frutas e carnes no grupo tratado com BCP $(43 \%, n=3)$ e no tratamento combinado $(14 \%, n=1)$.

Não houve diferenças significativas em comportamentos adaptativos, avaliados pelo escore ABAS-II ou de comportamentos repetitivos, avaliados pelo escore RBS-R. Todavia, foram notadas reduções importantes nos comportamentos aberrantes, avaliados pelo escore $A B C$. Nos pacientes em tratamento exclusivo com BCP, foram notadas reduções nos escores dos quesitos de "irritabilidade" (-6.375, $p=0.003)$, "estereotipia" $(-3.0, p=0.006)$, "hiperatividade" $(-6.25, p=0.007)$ e no "escore total" (-21.5, $\mathrm{p}=0.006)$; foi percebido, também, uma tendência à redução significativa do escore em "letargia" ( $p=0.076)$. Em relação aos pacientes em uso do tratamento combinado, houve uma redução do escore de "letargia" (-2.0, $\mathrm{p}=0.0499$ ).

Não houve mudanças globais significantes na microbiota fecal dos pacientes ou nos perfis de metabólitos, segundo amostras de sangue, urina e fezes. Houve, porém, uma redução da frequência de células TCD4+/IL-13+ no tratamento combinado $(p=0.006)$ e da frequência de células TCD8+/TNF- $\alpha+$ no tratamento com BCP $(-7.9 \%$, $p=0.024$ ).

\section{ARTIGO 6}

Liu et al. publicaram, em 2019, um estudo randomizado, duplo-cego, que avaliou os efeitos do uso de um probiótico contendo $3 \times 10^{10}$ ufc/cápsula de Lactobacillus plantarum PS128 em crianças diagnosticadas com TEA. O estudo reuniu 71 meninos, entre 7 a 15 anos de idade, com o diagnóstico de TEA baseado no DSM-V (Diagnostic and Statistical Manual of Mental Disorders - 5th edition) e reforçado pelo ADI-R (Autism Diagnostic Interview-Revised). Os pacientes foram divididos em 02 grupos, o grupo placebo e o grupo que fez o uso do probiótico em questão. 0 tratamento durou cerca de 04 semanas. Foram aplicados alguns escores de comportamento, como o ABC-T (Autism Behavior Checklist-Taiwan version), SRS (Social Responsiveness Scale), CBCL (Child Behavior Checklist), SNAP-IV (Swanson, Nolan and Pelham-IV), CGI-I (Clinical Global Impression-Improvement) e CGI-S (Clinical Global Impression-Severity). Os pacientes foram avaliados em duas visitas, no 10 dia e ao final da 4a semana, onde ocorreu a aplicação dos escores já citados, associada a uma avaliação médica completa em ambas visitas.

Ao final das 4 semanas, a pontuação de todos os escores nos grupos PS128 e placebo permaneceram similares em relação às pontuações do $1^{\circ}$ dia (baseline). Apesar disso, foram realizadas análises exploratórias de cada uma das categorias destes escores. Em relação à pontuação do escore CGI-I, ambos grupos, PS128 e placebo, obtiveram uma pontuação equivalente a "minimamente melhorado" (3.64 e 3.66, respectivamente; $p=0.94$ ). Segundo o escore $A B C-T$, foi notada uma tendência mínima à redução da pontuação na categoria "uso do corpo e de objetos" ( $p=0.04)$. Conforme o SRS, foi notada uma redução significante do escore total do grupo PS128 $(p=0.04)$. Houve uma redução, a partir do escore $C B C L$, das pontuações em "ansiedade" ( $p=0.02)$ e "comportamentos transgressores" ( $p=0.02)$ no grupo PS128 e uma redução em "problemas relacionados à externalização" $(p=0.02)$ no grupo placebo. Segundo o escore SNAP-IV, houve uma redução das pontuações total $(p=0.01)$, "hiperatividade e impulsividade" ( $p=0.04)$ e "oposição e desafio" $(p=0.045)$ no grupo PS128.

\section{ARTIGO 7}

Um ensaio clínico conduzido por Wang et al. (2020) avaliou o uso de probióticos associado a fruto-oligossacarídeos (FO) quanto a melhora de sintomas de TEA e ao efeito modulador sobre a microbiota intestinal, ácidos graxos de cadeia curta (AGCC), neurotransmissores. Foram incluídas no estudo 26 crianças com diagnóstico de TEA e 24 crianças neurotípicas entre 3 e 9 anos. Foram considerados como critérios de exclusão: uso de antibióticos, probióticos ou prebióticos nos últimos 3 meses; uso de drogas nutricionais; complicações de hiperatividade e uso de aripripazol e outros psicotrópicos. Os participantes permaneceram 12 meses em um hospital consumindo a dieta fornecida pela instituição.

Os participantes foram avaliados antes do início da intervenção (dia 0) e 30, 60 e 108 dias após. Foram coletados dados clínicos de gravidade dos sintomas de TEA pelo questionário Autism Treatment Evaluation Checklist (ATEC) e de sintomas gastrointestinais pelo 6-GI Severity Index. Também foram realizadas dosagem de AGCCs, neurotransmissores e zolunina em amostra de sangue $e$ 
análise da microbiota por sequenciamento de 16s rRNA em amostras de fezes.

Na primeira etapa do estudo, antes da intervenção, as amostras foram analisadas e comparadas entre o grupo com TEA e dos neurotípicos. As amostras de fezes foram analisadas para caracterização da microbiota intestinal e comparação entre o grupo com TEA e os neurotípicos. Os resultados mostraram um aumento significativo da quantidade relativa de Ruminococuus e Clostridium e uma redução significativa de Actinobacteria, Bifidobacterium, Bifidobacteriales, Bifidobacteriaceae e B. logum no grupo com TEA em comparação aos neurotípicos.

Comparando as dosagens de AGCCs nas fezes entre os dois grupos, foram encontrados níveis significativamente reduzidos dos ácidos acético, butírico e propiônico no grupo com TEA. Não houve diferenças significativas entre os dois grupos nos níveis dos ácidos isobutírico, valérico, isovalérico e caproico.

Foram analisadas as amostras de plasma para dosagem de neurotransmissores e comparação dos resultados entre os grupos com TEA e os neurotípicos. Os resultados mostraram níveis significativamente maiores de $5-\mathrm{HT}$, ácido hidroxiindolacetico, L-glutamina, L-arginina, L-histidina e L-histamina entre os participantes com TEA. O mesmo grupo também apresentou níveis significativamente menores de quinurenina e HVA. Não foram encontradas diferenças significativas entre os grupos nos níveis de L-tirosina, L-dopa, ácido vanililmandílico, ácido L-glutâmico, acetilcolina e GABA.

Na segunda etapa do estudo, os participantes portadores de TEA foram divididos em um grupo placebo $(n=10)$ e um grupo intervenção $(n=16)$, que fez uso de FO e probióticos por 108 dias. Estes continham cepas de Bifidobacterium infantis Bi-26, Lactobacillus rhamnosus HN001, Bifidobacterium lactis BL-04, e Lactobacillus paracasei LPC-37 (1010UFC/pacote/dia). Os resultados mostraram que a partir de 60 dias até o fim do estudo houve uma redução significativa no grupo intervenção dos escores ATEC total e nas categorias fala/linguagem/ comunicação e sociabilidade.

Em relação aos sintomas gastrointestinais, o grupo intervenção apresentou uma melhora significativa com redução dos escores 6-GSI total e nos itens constipação e odor das fezes a partir de 30 dias até o fim do estudo. Adicionalmente, a partir de 60 dias até o fim do estudo houve redução significativa do escore no item diarréia.

As amostras de fezes foram analisadas e comparadas entre o grupo placebo, grupo intervenção e grupo controle. Em relação à composição da microbiota intestinal, a análise da diversidade alfa revelou que os índices do grupo intervenção reduziram gradualmente e se aproximaram dos índices do grupo controle. A análise da diversidade beta mostrou diferenças significativas no grupo intervenção comparando o dia 0 e o dia 108, entretanto não foram encontradas diferenças no grupo placebo. Houve um aumento significativo de Bifidobacteriales e $B$. longum no grupo intervenção e uma redução de Clostridium e Ruminococcus em ambos, sendo mais acentuada no grupo intervenção.

Quanto aos níveis de AGCCs, houve um aumento dos níveis dos ácidos acético, butírico e propiônico no grupo intervenção que se aproximaram dos níveis do grupo controle. $O$ grupo placebo, no entanto, não apresentou diferenças significativas.

A dosagem de neurotransmissores mostrou uma meIhora significativa nos níveis de L-triptofano, 5-HT, ácido 5-hidroxiindoleacetico, quinurenina e ácido homovalínico do grupo intervenção, apresentando níveis similares do grupo controle.

Em relação ao marcador bioquímico zonulina, os resultados mostraram que seus níveis foram maiores no grupo com TEA em comparação com o grupo controle e após a intervenção houve uma redução para níveis similares do grupo controle.

\section{ARTIGO 8}

Em 2019, Arnold et al. avaliaram o efeito do uso do probiótico VISBIOME nos sintomas clínicos e na qualidade de vida de 10 crianças de 3 a 12 anos diagnosticadas com TEA. O protocolo foi realizado com uma primeira fase de 8 semanas de tratamento ou placebo, seguido de 3 semanas de abstinência e uma segunda fase de 8 semanas de tratamento ou placebo. Os participantes foram divididos em um grupo que usou o tratamento na primeira fase e placebo na segunda fase e outro que seguiu o protocolo na ordem inversa. Foram avaliados sintomas gastrointestinais pela pontuação no módulo respectivo da escala Pediatric Quality of Life Inventory (PedsQL), sintomas de ansiedade pela escala Parent-Rated Anxiety Scale for ASD (PRAS-ASD), sintomas de comportamento aberrante pela Aberrant Behaviour Checklist, qualidade dos hábitos de sono pela CSHQ score, o nível comprometimento da sociabilidade pela Social Responsiveness Scale, e o nível de estresse na relação entre a criança e os pais pelo questionário The Parenting Stress Index Short Form. Também foi aplicada a escala Target Symptom Rating, que consiste em registrar as duas queixas mais importantes do responsável pela criança e quantificar sua evolução através da análise de clínicos "cegos" em relação grupo do participante.

Os resultados da comparação entre a fase de placebo e de tratamento mostraram que houve uma melhora estatisticamente significante na primeira queixa avaliada pelo Target Symptom Rating ( $p=0.02)$, porém não houve diferença estatisticamente significante em relação aos sintomas gastrointestinais, de ansiedade, sono, sociabilidade e comportamento aberrante. Trata-se de um estudo piloto com o objetivo de avaliar a segurança e factibilidade de futuros estudos mais aprofundados. 
Tabela 1 - Características dos estudos relativos ao uso de probiótico na esquizofrenia incluídos na presente revisão.

\begin{tabular}{|c|c|c|c|c|c|c|c|c|c|}
\hline $\begin{array}{l}\text { Primeiro Autor, } \\
\text { ano, (Referên- } \\
\text { cia) }\end{array}$ & País & Amostra (n) & $\begin{array}{l}\text { Desenho do } \\
\text { estudo }\end{array}$ & Probiótico & Duração & Idade & $\begin{array}{l}\text { Resultado } \\
\text { (Diferenças esta- } \\
\text { tísticas) }\end{array}$ & $\begin{array}{l}\text { Resultado } \\
\text { (Sem diferenças } \\
\text { estatísticas) }\end{array}$ & $\begin{array}{l}\text { Efeitos } \\
\text { Adversos }\end{array}$ \\
\hline $\begin{array}{l}\text { Severance et al., } \\
\text { 2017, (SEVER- } \\
\text { ANCE et al., } \\
\text { 2017) }\end{array}$ & EUA & 56 & $\begin{array}{l}\text { Randomizado, } \\
\text { duplo cego, contro- } \\
\text { lado por placebo }\end{array}$ & $\begin{array}{l}10^{9} \text { Lactobacillus rhamnosus } \\
\text { strain GG } 10^{9} \text { cfus of Bifidobacte- } \\
\text { rium animalis subsp. lactis Bb12 }\end{array}$ & $\begin{array}{l}14 \text { sema- } \\
\text { nas }\end{array}$ & $18-65$ anos & $\begin{array}{l}\downarrow C \text {. albicans } \lg G \\
\text { (homens) }\end{array}$ & & \\
\hline $\begin{array}{l}\text { Tomasik et al., } \\
\text { 2015, (TOMASIK } \\
\text { et al., 2015) }\end{array}$ & EUA & 58 & $\begin{array}{l}\text { Randomizado, } \\
\text { duplo cego, contro- } \\
\text { lado por placebo }\end{array}$ & $\begin{array}{l}10^{9} \mathrm{~L} \text {. rhamnosus } \mathrm{GG} \\
10^{9} \text { Bifidobacterium animalis } \\
\text { subsp. Lactis Bb12 }\end{array}$ & $\begin{array}{l}14 \text { sem- } \\
\text { anas }\end{array}$ & $18-65$ anos & $\begin{array}{l}\downarrow V W F, \uparrow M C P-1, \\
\uparrow B D N F, \uparrow M I P-1 \beta, \\
\uparrow R A N T E S\end{array}$ & & \\
\hline $\begin{array}{l}\text { Dickerson et al. } \\
\text { 2014, (DICK- } \\
\text { ERSON et al., } \\
\text { 2014) }\end{array}$ & EUA & 58 & $\begin{array}{l}\text { Randomizado, } \\
\text { duplo cego, contro- } \\
\text { lado por placebo }\end{array}$ & $\begin{array}{l}10^{9} \mathrm{~L} \text {. rhamnosus } \mathrm{GG} \\
10^{9} \text { Bifidobacterium animalis } \\
\text { subsp. Lactis Bb12 }\end{array}$ & $\begin{array}{l}14 \text { sem- } \\
\text { anas }\end{array}$ & $18-65$ anos & $\begin{array}{l}\text { Grupo probiótico } \\
\text { foi menos pro- } \\
\text { penso a relatar } \\
\text { dificuldade severa } \\
\text { em defecar }\end{array}$ & $\begin{array}{l}\text { Uso de laxantes } \\
\text { ou experiência } \\
\text { de diarreia; } \\
\text { PANSS escore } \\
\text { total; }\end{array}$ & \\
\hline $\begin{array}{l}\text { Okubo et al., } \\
\text { 2018, (OKUBO et } \\
\text { al., 2018) }\end{array}$ & Japão & 29 & $\begin{array}{l}\text { Ensaio aberto, } \\
\text { ramo único }\end{array}$ & $\begin{array}{l}10^{11} \text { ufc/dia de Bifidobacterium } \\
\text { breve A-1 }\end{array}$ & $\begin{array}{l}08 \text { sema- } \\
\text { nas }\end{array}$ & Mediana de 46 anos & $\begin{array}{l}\downarrow \text { HADS (4a } \\
\text { semana); } \downarrow \text { PANSS } \\
\text { (4 e e } 8 \text { a semana); } \\
\text { 个IL-22; } \uparrow \text { TRANCE; } \\
\downarrow \text { TNF- } \alpha\end{array}$ & $\begin{array}{l}\text { HADS (8ª sema- } \\
\text { na); Manutenção } \\
\text { dos níveis de } \\
\text { Bifidobacterium } \\
\text { (basal, 4ª e 8a } \\
\text { semana); }\end{array}$ & \\
\hline $\begin{array}{l}\text { Ghaderi et al., } \\
\text { 2019, (GHADERI } \\
\text { et al., 2019) }\end{array}$ & Irã & 60 & $\begin{array}{l}\text { Randomizado, } \\
\text { duplo cego, contro- } \\
\text { lado por placebo }\end{array}$ & $\begin{array}{l}8 \times 10^{9} \text { ufc/dia de Lactobacillus } \\
\text { acidophilus, Bifidobacterium } \\
\text { bifidum, } \\
\text { Lactobacillus reuteri, e Lactoba- } \\
\text { cillus fermentum }\end{array}$ & $\begin{array}{l}12 \text { sema- } \\
\text { nas }\end{array}$ & $\begin{array}{l}\text { Grupo placebo: } 43.2 \\
\pm 6.0 \\
\text { Grupo tratamento: } \\
44.8 \pm 8.3\end{array}$ & $\begin{array}{l}\downarrow \text { PANSS Total } \\
\downarrow \text { PANSS Sub- } \\
\text {-escala negativo } \downarrow \\
\text { PANSS Sub-escala } \\
\text { geral }\end{array}$ & $\begin{array}{l}\downarrow \text { PANSS Sub- } \\
\text {-escala positivo } \\
\uparrow \text { BPRS }\end{array}$ & \\
\hline
\end{tabular}

Nota: EUA: Estados Unidos da América; Duração: duração do tratamento; ufc/dia: Unidades formadoras de colônia/dia; vWF: Fator de von Willebrand; PANSS: Positive and Negative Syndrome Scale; HADS: Hospital Anxiety Depression Scale; TRANCE: TNF-relatedactivation-induced cytokine; IL-22: citocina envolvida na reparação tecidual; TNF- $\alpha$ : citocina pró-inflamatória; MCP1: proteína de quimioatração de monócitos; BDNF: Fator Neurotrófico Derivado do Cérebro; RANTES: quimiocina CCL5; MIP-1ß: proteína inflamatória de macrófagos-1 beta; BPRS: Brief Psychiatric Rating Scale.

Tabela 2 - Características dos estudos relativos ao uso de probiótico no Transtorno do Espectro Autista incluídos na presente revisão

\begin{tabular}{|c|c|c|c|c|c|c|c|c|c|}
\hline $\begin{array}{l}\text { Primeiro Autor, } \\
\text { ano, (Referência) }\end{array}$ & País & Amostra (n) & $\begin{array}{l}\text { Desenho do } \\
\text { Estudo }\end{array}$ & Probiótico & Duração & Idade & $\begin{array}{l}\text { Resultado } \\
\text { (Diferenças } \\
\text { estatísticas) }\end{array}$ & $\begin{array}{c}\text { Resultado } \\
\text { (Sem diferenças } \\
\text { estatísticas) }\end{array}$ & $\begin{array}{c}\text { Efeitos } \\
\text { Adversos }\end{array}$ \\
\hline $\begin{array}{l}\text { Kałuzna- } \\
\text { Czaplińska, } \\
\text { 2012, (KAŁUZ- } \\
\text { NA-CZAPLIŃSKA; } \\
\text { BŁASZCZYK, 2012) }\end{array}$ & Polônia & $\begin{array}{l}22 \text { crianças com } \\
\text { TEA }\end{array}$ & Estudo coorte & $\begin{array}{l}\text { Lactobacillus acidophilus } \\
\left(5 \times 10^{9} / \mathrm{g}\right)\end{array}$ & 2 meses & 4-10 anos & $\begin{array}{l}\text { 个concentração } \\
\text { 个habilidade de } \\
\text { seguir ordens }\end{array}$ & $\begin{array}{l}\text { Resposta compor- } \\
\text { tamental ao sen- } \\
\text { timento de outras } \\
\text { pessoas / contato } \\
\text { com os olhos }\end{array}$ & \\
\hline $\begin{array}{l}\text { Tomova et al., } \\
\text { 2014, (TOMOVA et } \\
\text { al., 2015) }\end{array}$ & Eslováquia & $\begin{array}{l}29 \text { crianças } \\
\text { (10 com TEA; } 9 \\
\text { irmãos sem TEA } \\
\text { e } 10 \text { sem TEA } \\
\text { [controle]). }\end{array}$ & Estudo coorte & $\begin{array}{l}\text { "Children Dophilus" } \\
\text { Lactobacillus (60\%), } \\
\text { Bifidumbacteria (25\%) } \\
\text { Streptococcus (15\%); }\end{array}$ & 4 meses & 2-17 anos & $\begin{array}{l}\downarrow T N F-\alpha \\
\uparrow \text { Lactobacilli } \\
\downarrow \text { Firmicutes } \\
\downarrow \text { Bifidobacte- } \\
\text { rium }\end{array}$ & $\begin{array}{l}\text { Streptococcus } \\
\text { thermophillus }\end{array}$ & \\
\hline $\begin{array}{l}\text { Shaaban et al., } \\
\text { 2017, (SHAABAN et } \\
\text { al., 2017) }\end{array}$ & Egito & $\begin{array}{l}30 \text { crianças com } \\
\text { TEA } \\
\text { (19 meninos e } 11 \\
\text { meninas) }\end{array}$ & $\begin{array}{l}\text { Propectivo, } \\
\text { aberto }\end{array}$ & $\begin{array}{l}\text { Lactobacillus acidophilus, } \\
\text { Lactobacillus rhamnosus, } \\
\text { Bifidobacteria longum. } \\
\text { (dose diária de } 5 \mathrm{~g} \text { de pó, } \\
\text { cada grama contém } 100 \\
\times 10^{6} \text { ) }\end{array}$ & 3 meses & 5-9 anos & $\begin{array}{l}\uparrow \text { Bifidobacteria; } \\
\uparrow \text { Lactobacilli; } \\
\downarrow \text { peso corporal; } \\
\downarrow \text { severidade } \\
\text { do TEA (ATEC); } \\
\downarrow \text { sintomas gas- } \\
\text { trointestinais; }\end{array}$ & & $\begin{array}{l}\text { Não men- } \\
\text { cionado }\end{array}$ \\
\hline $\begin{array}{l}\text { Grossi et al., } \\
\text { 2016, (GROSSI et } \\
\text { al., 2016) }\end{array}$ & Itália & $\begin{array}{l}1 \text { criança com } \\
\text { TEA }\end{array}$ & Estudo de caso & VSL\#3 & $\begin{array}{l}4 \text { sema- } \\
\text { nas }+4 \\
\text { meses de } \\
\text { acompa- } \\
\text { nhamen- } \\
\text { to }\end{array}$ & 12 anos & 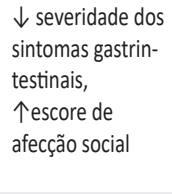 & & $\begin{array}{l}\text { Não men- } \\
\text { cionado }\end{array}$ \\
\hline
\end{tabular}

Nota: EUA: Estados Unidos da América; Duração: duração do tratamento; VSL\#3: Mix de probióticos contendo $9 \times 10^{10}$ bifidobacteria liofilizada (Bifidobacterium breve, B. longum, B. infantis), $8 \times 10^{10}$ lactobacilli (Lactobacillus acidophilus, L. plantarum, L. paracasei, L. bulgaricus, L. delbrueckii subsp.) e $20 \times 10^{10}$ Streptococci (S. thermophilus, S. salivarius subsp.); TNF- $\alpha$ : Fator de Necrose Tumoral Alfa ; TEA: Transtorno do Espectro Autista 
Tabela 2 - Características dos estudos relativos ao uso de probiótico no Transtorno do Espectro Autista incluídos na presente revisão

\begin{tabular}{|c|c|c|c|c|c|c|c|c|c|}
\hline $\begin{array}{l}\text { Primeiro Autor, } \\
\text { ano, [Refe- } \\
\text { rência] }\end{array}$ & País & $\begin{array}{l}\text { Amostra } \\
\text { (n) }\end{array}$ & $\begin{array}{l}\text { Desenho do } \\
\text { Estudo }\end{array}$ & Probiótico & Duração & Idade & $\begin{array}{l}\text { Resultado } \\
\text { (Diferenças esta- } \\
\text { tísticas) }\end{array}$ & $\begin{array}{l}\text { Resultado } \\
\text { (Sem diferenças esta- } \\
\text { tísticas) }\end{array}$ & $\begin{array}{l}\text { Efeitos Ad- } \\
\text { versos }\end{array}$ \\
\hline $\begin{array}{l}\text { Sanctuary } \\
\text { et al., 2019, } \\
\text { (SANCTUARY et } \\
\text { al., 2019) }\end{array}$ & EUA & $\begin{array}{l}8 \text { crianças } \\
\text { com TEA } \\
\text { associado } \\
\text { a sintomas } \\
\text { gastrointes- } \\
\text { tinais }\end{array}$ & $\begin{array}{l}\text { Ensaio clínico } \\
\text { randomizado, } \\
\text { duplo-cego }\end{array}$ & $\begin{array}{l}0.15 \mathrm{~g} / \mathrm{lb} / \text { dia de } \\
\mathrm{BCP} \text { ou } \mathrm{BCP}+ \\
2.10^{10} \mathrm{ufc} / \mathrm{dia} \text { de } \\
\text { Bifidobacterium } \\
\text { infantis }\end{array}$ & $\begin{array}{l}12 \text { semanas: } \\
05 \text { semanas } \\
\text { de tratamento } \\
\text { com probiótico, } \\
\text { seguidas de } 02 \\
\text { semanas sem } \\
\text { tratamento, } \\
\text { com mais } 05 \\
\text { semanas de uso } \\
\text { de probiótico + } \\
\text { prebiótico }\end{array}$ & $\begin{array}{l}02-11 \\
\text { anos }\end{array}$ & 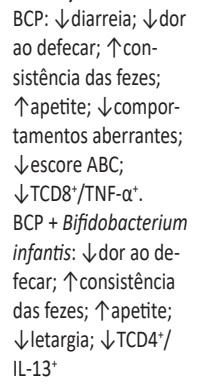 & $\begin{array}{l}\text { Comportamentos adap- } \\
\text { tativos (ABAS-II); com- } \\
\text { portamentos repetitivos } \\
\text { (RBS-R); microbiota fecal; } \\
\text { perfis de metabólitos nas } \\
\text { amostras de urina, sangue } \\
\text { e fezes; frequência de } \\
\text { células TCD4 } 4^{+} \text {ou TCD8 } \\
\text { que expressam INF- } \gamma \text {, } \\
\text { IL-17 ou IL-6. }\end{array}$ & $\begin{array}{l}\text { Gases }(n=2) \text { e } \\
\text { dor de estô- } \\
\text { mago }(n=1) \text { no } \\
\text { grupo de BCP; } \\
\text { ganho de peso } \\
(n=2) \text {, gases } \\
(n=2) \text { no grupo } \\
B C P+\text { Bifidobac- } \\
\text { terium }\end{array}$ \\
\hline $\begin{array}{l}\text { Liu et al., 2019, } \\
\text { (LIU et al., } \\
\text { 2019) }\end{array}$ & Taiwan & $\begin{array}{l}71 \text { meninos } \\
\text { com TEA }\end{array}$ & $\begin{array}{l}\text { Ensaio clínico } \\
\text { randomizado, } \\
\text { duplo-cego, } \\
\text { com placebo }\end{array}$ & $\begin{array}{l}3 \times 10^{10} \text { ufc/cáp- } \\
\text { sula de Lactoba- } \\
\text { cillus plantarum } \\
\text { PS128 }\end{array}$ & 04 semanas & $\begin{array}{l}07-15 \\
\text { anos }\end{array}$ & $\begin{array}{l}\downarrow \text { comportamentos } \\
\text { transgressores; } \\
\downarrow \text { hiperatividade e } \\
\text { impulsividade }\end{array}$ & $\begin{array}{l}\text { Comportamentos avalia- } \\
\text { dos por todos os escores } \\
\text { do estudo (ABC-T, CBCL, } \\
\text { SNAP-IV). }\end{array}$ & $\begin{array}{l}\text { Não mencio- } \\
\text { nados }\end{array}$ \\
\hline $\begin{array}{l}\text { Wang et al., } \\
\text { 2020, (WANG et } \\
\text { al., 2020) }\end{array}$ & China & $\begin{array}{l}26 \text { crianças } \\
\text { com TEA e } \\
24 \text { neurotí- } \\
\text { picas }\end{array}$ & $\begin{array}{l}\text { Ensaio clínico } \\
\text { randomizado, } \\
\text { duplo-cego, } \\
\text { controlado com } \\
\text { placebo }\end{array}$ & $\begin{array}{l}\text { Bifidobacterium } \\
\text { infantis Bi-26, } \\
\text { Lactobacillus } \\
\text { rhamnosus } \\
\text { HN001, } \\
\text { Bifidobacterium } \\
\text { lactis BL-04, e } \\
\text { Lactobacillus } \\
\text { paracasei } \\
\text { LPC-37 (10 } 10^{10} \text { ufc/ } \\
\text { pacote/dia). }\end{array}$ & $\begin{array}{l}12 \text { meses de } \\
\text { período pré- } \\
\text {-intervenção } \\
\text { e } 108 \text { dias de } \\
\text { intervenção }\end{array}$ & $\begin{array}{l}03-09 \\
\text { anos }\end{array}$ & $\begin{array}{l}\downarrow \text { severidade do TEA: } \\
\downarrow \text { escore ATEC total } \\
\text { (60 e } 108 \text { dias após } \\
\text { intervenção) } \\
\downarrow \text { escore ATEC } \\
\text { subescala fala/lingua- } \\
\text { gem/ comunicação } \\
\text { (60 e } 108 \text { dias após } \\
\text { intervenção) } \\
\downarrow \text { escore ATEC } \\
\text { subescala sociabilida- } \\
\text { de (60 e } \\
108 \text { dias após inter- } \\
\text { venção) } \\
\downarrow \text { sintomas gastroin- } \\
\text { testinais: } \\
\downarrow \text { escore 6-GSI total } \\
\downarrow \text { escore 6-GSI subes- } \\
\text { cala constipação } \\
\downarrow \text { escore 6-GSI subes- } \\
\text { cala odor das fezes } \\
\downarrow \text { escore 6-GSI } \\
\text { subescala diarréia } \\
\text { (60 e 108 dias após } \\
\text { intervenção) }\end{array}$ & $\begin{array}{l}\text { Severidade do TEA: } \\
\downarrow \text { escore ATEC total (30 } \\
\text { dias após intervenção) } \\
\downarrow \text { escore ATEC subescala } \\
\text { sensibilidade sensorial/ } \\
\text { cognitiva } \\
\downarrow \text { escore ATEC subescala } \\
\text { saúde/físico/compor- } \\
\text { tamento } \\
\text { Sintomas gastrointes- } \\
\text { tinais: } \\
\downarrow \text { escore 6-GSI subescala } \\
\text { diarréia (30 dias após } \\
\text { intervenção) } \\
\downarrow \text { escore 6-GSI subescala } \\
\text { dor abdominal } \\
\downarrow \text { escore 6-GSI subescala } \\
\text { flatulência } \\
\downarrow \text { escore 6-GSI subescala } \\
\text { consistência das fezes }\end{array}$ & Não houve \\
\hline $\begin{array}{l}\text { Arnold et al., } \\
\text { 2019, (ARNOLD } \\
\text { et al., 2019) }\end{array}$ & EUA & 13 & $\begin{array}{l}\text { Estudo piloto } \\
\text { randomizado, } \\
\text { duplo cego, } \\
\text { controlado por } \\
\text { placebo }\end{array}$ & $\begin{array}{l}10^{10} \text { ufc/dia de } \\
\text { Lactobacillus } \\
\text { reuteri }\end{array}$ & 19 semanas & $\begin{array}{l}03-12 \\
\text { anos }\end{array}$ & $\begin{array}{l}\downarrow \text { sintoma principal } \\
\text { relatado do partici- } \\
\text { pante: } \\
\downarrow \text { Target sympton No. } \\
1 \text { (desvio padrão) }\end{array}$ & $\begin{array}{l}\downarrow 2 \text { sintomas principais } \\
\text { relatado do participante: } \\
\downarrow \text { Target symptons } \\
\text { (média) } \\
\downarrow \text { PRAS-ASD total } \\
\uparrow \text { PedsQL GI total } \\
\uparrow \text { PSI total } \\
\downarrow \text { SRS total } \\
\uparrow \text { CSHQ total } \\
\uparrow A B C(1) \text { irritabilidade } \\
\downarrow A B C(2) \text { letargia } \\
\uparrow A B C(3) \text { estereotipia } \\
\uparrow A B C \text { (4) hiperatividade } \\
\downarrow A B C \text { (5) fala inapro- } \\
\text { priada } \\
\text { Caracterização da } \\
\text { microbiota: } \\
\text { Não houve diferenças } \\
\text { significativas entre os } \\
\text { grupos na composição ou } \\
\text { complexidade da micro- } \\
\text { biota nas fezes }\end{array}$ & $\begin{array}{l}\text { Não houve } \\
\text { diferenças } \\
\text { estatisticamente } \\
\text { significantes } \\
\text { comparando a } \\
\text { ocorrência de } \\
\text { efeitos adversos } \\
\text { entre o grupo } \\
\text { intervenção e o } \\
\text { grupo placebo }\end{array}$ \\
\hline
\end{tabular}

Nota: EUA: Estados Unidos da América; Duração: duração do tratamento; TEA: Transtorno do Espectro Autista; lb: Libra (0.45kg); BCP: produto do colostro bovino; ufc: unidade formadora de colônia; TNF- $\alpha$ : Fator de Necrose Tumoral Alfa; IL-13: citocina mediadora de processos inflamatórios alérgicos; ABC-T (Autism Behavior Checklist-Taiwan version); SRS (Social Responsiveness Scale); CBCL (Child Behavior Checklist); SNAP-IV (Swanson, Nolan and Pelham-IV); ATEC (Autism Treatment Evaluation Checklist); 6-GSI (6-Item Gastrointestinal Severity Index); PRAS-ASD (Parent-Rated Anxiety Scale for autism spectrum disorders); PedsQL GI (Pediatric Quality of Life Gastrointestinal); PSI (Parenting Stress Index); CSHQ (Children's Sleep Habits Questionnaire); ABC (Autism Behavior Checklist) 


\section{DISCUSSÃO}

\section{ESQUIZOFRENIA}

Ancorado nas evidências apresentadas anteriormente, foram observados resultados controversos sobre o efeito de probiótico na diminuição dos sintomas clínicos gerais da esquizofrenia, conforme a escala de PANSS total. Todavia, em todas as pesquisas em que foi avaliado (DICKERSON et al., 2014; GHADERI et al., 2019), houve uma melhora da função gastrointestinal, a qual é agravada pelo uso de antipsicóticos, sendo a constipação presente em até $60 \%$ dos pacientes com esquizofrenia(SEVERANCE et al., 2015). Além disso, há o impacto na qualidade de vida do paciente, a qual também precisa ser levada em conta. Todavia, tal aspecto não foi claramente abordado pelos estudos incluídos.

A redução dos níveis de vWF encontrada por Tomasik et al., parece refletir uma diminuição da inflamação, haja vista que este é um fator positivo de reação aguda à injuria do endotélio, refletindo dessa forma, um menor nível de lesão. Associado a esses dados, foi encontrado um aumento da expressão de TRANCE e de IL-22 (OKUBO et al., 2018), proteínas que estão envolvidas no processo de manutenção e regeneração da barreira epitelial intestinal (KEIR et al., 2020; NAGASHIMA et al., 2017). Assim, podemos hipotetizar que a produção e manutenção das junções de oclusões no epitélio intestinal está associada à microbiota, e sendo esta fundamental para diminuir a translocação bacteriana do intestino para a corrente sanguínea e consequente diminuição da inflamação via receptores TLR(KOBOZIEV et al., 2014). Isso, poderia explicar parcialmente o resultado distinto encontrado por Ghaderi et al. na escala PANSS total, com a junção de vitamina $\mathrm{D}$ ao uso de probióticos, a qual está associada a manutenção das junções de oclusão(STIO et al., 2016). Para a confirmação, faz-se necessário mais estudos que possam mensurar os níveis de LPS e marcadores inflamatórios como TNF- $\alpha$ e IL-1, assim como os marcadores associados a junções de oclusão, a exemplo da proteína zonulina.

No estudo de Okubo et al. foi observado que os pacientes do grupo "responsivos" consumiam significativamente menos laticínios do que aqueles pertencentes ao grupo de "arresponsivos"(OKUBO et al., 2018). Em uma metanálise conduzida em 2017 por Li et al., foi demonstrada uma relação entre o consumo de laticínios com alto teor de gordura e o aumento do risco de desenvolver depressão (LI et al., 2017). Em contraste, Miyake et al., em 2015, encontrou uma relação entre o consumo de iogurte e um menor risco de desenvolver depressão em mulheres grávidas("Intake of dairy products and calcium and prevalence of depressive symptoms during pregnancy in Japan : a cross-sectional study", 2014). A partir dos resultados expostos, é possível teorizar que existe uma provável relação entre a resposta clínica obtida a partir do tratamento com probióticos e o consumo de laticínios, sendo um campo de necessária análise nos estudos posteriores, o que poderia explicar alguns resultados controversos.

Foi encontrado também uma diminuição da severidade dos sintomas ansiosos e depressivos (OKUBO et al., 2018). Esse resultado corrobora os resultados já discutidos anteriormente associados à diminuição da inflamação, a qual já foi descrita a sua relação com a patogênese dessas doenças, a exemplo da modificação da expressão da enzima IDO no metabolismo de quinurenina (KENNEDY et al., 2017).

\section{LIMITAÇÕES}

Três dos trabalhos publicados (DICKERSON et al., 2014; SEVERANCE et al., 2017; TOMASIK et al., 2015), como já citado anteriormente, são provenientes de um mesmo estudo, de forma que, refletem informações de um mesmo grupo. Além disso os probióticos foram utilizados em pacientes em uso de antipsicóticos e clinicamente estáveis, de forma que, refletem apenas um estado da doença, ficando inconclusivo quanto à possibilidade das suas aplicações em outros períodos.

Apesar dos resultados promissores encontrados nos estudos de Okubo et al. 2018 e Ghaderi et al. 2019, o primeiro não possuía grupo controle e, no segundo, foi realizado um tratamento combinado, limitando a confiabilidade dos resultados.

Por último, todos os estudos foram realizados em pacientes com a doença já instalada, ficando um vasto campo de possibilidade de estudo na prevenção de pacientes com risco, conforme as evidências de que o período perinatal é um momento crítico para prevenção (JENKINS, 2013; JONES et al., 2014).

\section{AUTISMO}

\section{SINTOMAS CLÍNICOS}

$62,5 \%$ (5/8) dos estudos analisados, encontraram algum nível de modificação comportamental como resultado da intervenção de probióticos em crianças com TEA, utilizando-se de parâmetros clínicos distintos.

O resultado encontrado de redução dos valores da escala ATEC(SHAABAN et al., 2017) indica que o uso de probióticos pode diminuir a severidade da doença, principalmente dos que sofrem de mais queixas oriundas do aparelho gastrointestinal.

Em uma revisão sistemática de 2017 publicada no jornal Pediatrics, foi confirmado que crianças com TEA possuem taxa mais altas de diarreia (OR, 3,63; IC95\%, 1,82-7,23), constipação (OR, 3,86; IC95\%, 2,23-6,71) e dor abdominal (OR, 2,45; IC95\%, 1,19- 5,07) (BARBARA et al., 2014).

Os resultados encontrados sugerem que as alterações comportamentais podem ser mais significativas em categorias comportamentos específicos, a exemplo de comportamentos aberrantes e hiperatividade (LIU et al., 2019; SANCTUARY et al., 2019), sendo necessária 
futuras distinções dos efeitos nas diversas categorias comportamentais.

Adicionalmente, foram notadas mudanças mais significativas nos escores dos pacientes mais jovens (07-12 anos) em comparação aos mais velhos (13-15 anos)(LIU et al., 2019). Sugere-se, então, que intervenções mais precoces nos pacientes com TEA possam vir a gerar resultados mais promissores em termos de comportamento.

\section{BIOQUÍMICA}

Dois dos estudos analisaram os níveis de TNF- $\alpha$ associado à intervenção com probióticos encontrando resultados distintos(SANCTUARY et al., 2019; TOMOVA et al., 2015). Essa análise está em consonância com as evidências já encontradas de que pacientes com TEA, em comparação com indivíduos saudáveis, possuem taxas de TNF- $\alpha$, IL-6 e IL-17 significativamente maiores ( $p<0,0001$, $p=0,001$ e $p<0,0001$, respectivamente) (EFTEKHARIAN et al., 2018). Há também uma recente sugestão de que a etiologia do TEA estaria associada à uma inflamação durante a gestação. A ativação imune materna resultaria em liberação das citocinas pró inflamatórias interleucina 17a (IL-17a) pelos linfócitos T helper 17 (Th17) (BOULANGER-BERTOLUS; PANCARO; MASHOUR, 2018; OSOKINE; ERLEBACHER, 2017).

Essas evidências seriam reforçadas pelo resultado encontrado por Sanctuary et al., de redução da expressão de IL-13, visto que já foi notada a presença de altos níveis da mesma em crianças com TEA (MOLLOY et al., 2006), além da sua associação com doenças inflamatórias intestinais(MANNON; REINISCH, 1825), podendo explicar a redução dos sintomas gastrointestinais.

A redução da inflamação poderia explicar os resultados encontrados de diminuição da relação entre Bacteroidetes/Firmicutes, como já relatado em outros estudos (RIAL et al., 2016). Arnold et al. e Sanctuary et al., todavia, não encontraram mudanças significativas da composição global da microbiota dos pacientes, apesar da melhora dos sintomas, em contraste com os resultados positivos encontrados por Tomova et al. 2015 e Wang et al 2020.

\section{GASTROINTESTINAL}

Quatro dos estudos analisados avaliaram os efeitos da intervenção nos sintomas gastrointestinais, sendo unânimes na positividade da redução da severidade dos sintomas. Em especial, Sanctuary et al. descreveram a diminuição da dor ao defecar e aumento da consistência das fezes (SANCTUARY et al., 2019). Não foram relatados efeitos colaterais significativos.

\section{LIMITAÇÕES}

Cerca de 5 do total de 8 estudos $(62,5 \%)$ não apresentaram grupo placebo, o que compromete a veracidade dos resultados encontrados. Adicionalmente, 2 estudos não apresentaram um grupo com tratamento exclusivo com o probiótico em questão, dificultando a separação entre os benefícios do probiótico isolado (SANCTUARY et al., 2019; WANG et al., 2020). Além disso, foi encontrado uma grande a heterogeneidade metodológica. Foram avaliados em 4 dos 8 artigos (50\%) a composição da microbiota dos pacientes (ARNOLD et al., 2019; SANCTUARY et al., 2019; TOMOVA et al., 2015; WANG et al., 2020), o que dificulta a compreensão entre o tempo de intervenção e as mudanças globais na composição da microbiota dos pacientes.

Apesar dos resultados promissores do trabalho de Grossi et al., ele se resume a apenas um caso. Contudo, apesar dessa limitação metodológica, as evidências apontam para o potencial do tratamento personalizado, o qual foi utilizado conjuntamente a terapia psicomotora semanal e um plano de educação individualizado.

\section{CONCLUSÃO}

A presente revisão sugere que o uso de probióticos melhorou os sintomas gastrointestinais, associados à esquizofrenia. Contudo, não demonstrou evidências conclusivas quanto à redução dos sintomas psiquiátricos da esquizofrenia, conforme o escore PANSS total. Quanto aos efeitos adversos, não houve diferença significativa entre os pacientes participantes dos estudos incluídos que receberam probiótico ou placebo.

Quanto ao Transtorno do Espectro Autista, as evidências sugerem um possível potencial de eficácia do uso de probióticos na redução dos sintomas comportamentais associados à doença. Quanto à redução dos sintomas gastrointestinais, as evidências parecem apontar uma melhora. Não foram relatados efeitos adversos deletérios com a utilização do tratamento nos pacientes.

A grande divergência em relação aos desenhos de pesquisa e métodos e avaliação, impossibilita conclusões sólidas. Assim, são necessários mais estudos clínicos com dados primários, em amostras maiores, com grupos controles, que permitam avaliar o impacto do uso de probióticos em relação à melhora dos sintomas da esquizofrenia e do TEA, assim como em relação aos efeitos adversos. Além disso, são necessários estudos que apresentem uma maior duração de tratamento com os probióticos, para que se avalie o impacto dos mesmos na composição da microbiota dos pacientes e se existe correlação da meIhora ou não dos sintomas com alterações da microbiota.

\section{REFERÊNCIAS}

ARNOLD, L. E. et al. Probiotics for gastrointestinal symptoms and quality of life in autism : a placebo-controlled pilot trial. J. Child.Adolesc. Psychopharmacol., New York, v. 20, n.20, p. 1-11, 2019.

BARBARA O. M. et al. Gastrointestinal symptoms in autism spectrum disorder : a meta-analysis abstract. 2014.

BARON-COHEN, S. The cognitive neuroscience of autism. J. Neurol., Neuros. Psychiatry, London, v. 75, n. 7, p. 945-948, July 2004.

BARON-COHEN, S. et al. Prevalence of autism-spectrum conditions: UK school-based population study. Br. J. Psychiatr., London, v. 194, n. 06, p. 500-509, June 2009 . 
BOULANGER-BERTOLUS, J.; PANCARO, C.; MASHOUR, G. A. Increasing role of maternal immune activation in neurodevelopmental disorders. Front Behav Neuroci., [s.I], v. 12, p. 1-6, 2018.

BRANDSMA, E. et al. The immunity-diet-microbiota axis in the development of metabolic syndrome. Curr. Opin. Lipidol., London, v. 26, n. 2, p. 73-81, 2015.

CABALlERO, S.; PAMER, E. G. Microbiota-mediated inflammation and antimicrobial defense in the intestine. Ann. Rev. immunol., [s.I], v. 33, p. 227-256, 2015

DICKERSON, F. B. et al. Effect of probiotic supplementation on schizophrenia symptoms and association with gastrointestinal functioning. Prim. Care Companion CNS Disord., [s.I], v. 16, n. 1, 2014.

EFTEKHARIAN, M. M. et al. Cytokine profile in autistic patients. Cytokine, San Diego, v. 108, p. 120-126, 2018.

FOSTER, J. A.; MCVEY NEUFELD, K. A. Gut-brain axis: How the microbiome influences anxiety and depression. Trends Neurosc., Cambridge, v. 36, n. 5, p. 305-312, 2013.

GHADERI, A. et al. Clinical and metabolic response to vitamin D plus probiotic in schizophrenia patients. BMC Psychiatry, London, n. 77, p. 1-10, 2019.

GROSSI, E. et al. Unexpected improvement in core autism spectrum disorder symptoms after long-term treatment with probiotics. SAGE Open Medical Case Reports, [s.I], v. 4, p. 2050313X1666623, 2016.

GRIFFIN, de C.; HARDING, J.; SUTTON, C. Intake of dairy products and calcium and prevalence of depressive symptoms during pregnancy in Japan : a cross-sectional study. BJOG, Oxford, v.122, n. 4, p. 336-343, 2015.

JENKINS, T. A. Perinatal complications and schizophrenia: involvement of the immune system. Front. Neurosci., Lausanne, v. 7, n. 7, p. 1-9, June 2013.

JOHANSSON, M. E. V.; HANSSON, G. C. Immunological aspects of intestinal mucus and mucins. Nat. Rev. Immunol., London, v. 16, n. 10, p. 639-649, 2016.

JONES, I. et al. Bipolar disorder, affective psychosis, and schizophrenia in pregnancy and the post-partum period. Lancet, London, v. 384, n. 9956, p. 1789-1799, 2014.

KAŁUZNA-CZAPLIŃSKA, J.; BŁASZCZYK, S. The level of arabinitol in autistic children after probiotic therapy. Nutrition, [s.I], v. 28, n. 2, p. 124-126, 2012.

KANJI, S. et al. The microbiome-gut-brain axis: implications for schizophrenia and antipsychotic induced weight gain. Eur. Arch. Psy Clin. Neurosc., Berlim, p. 1-13, 2017.

KARAKUŁA-JUCHNOWICZ, H. et al. The brain-gut axis dysfunctions and hypersensitivity to food antigens in the etiopathogenesis of schizophrenia. Psychiatr. Pol., Warszawa, v. 50, n. 4, p. 747-760, 2016.

KEIR, M. E. et al. The role of IL-22 in intestinal health and disease. J. exp. med., New York, v. 217, n. 3, p. 1-9, 2020.

KENNEDY, P. J. et al. Kynurenine pathway metabolism and the microbiota- gut-brain axis. Neuropharmacology, Oxford, v. 112, p. 399-412, 2017.

KOBOZIEV, I. et al. Role of the enteric microbiota in intestinal homeostasis and inflammation. Free Rad. Biol. Med., New York, v. 68, p. 122-133, 2014.

LI, Y. et al. Dietary patterns and depression risk : a meta-analysis. Reveja, [s.I], v. 253, p. 373-382, 2017.

LIU, Y. W. et al. Effects of lactobacillus plantarum PS128 on children with autism spectrum disorder in Taiwan: A randomized, double-blind, placebo-controlled trial. Nutrients, [s.I.], v. 11, n. 4, p. 1-16, 2019.

LYTE, M.; CRYAN, J. F. Microbial endocrinology : the microbiota- gutbrain axis in health and disease. [s.l: s.n.].

MACFABE, D. F. Short-chain fatty acid fermentation products of the gut microbiome: implications in autism spectrum disorders. Microb. Ecol. Health Dis., Oslo, v. 23, n. 0, ago. 2012.

MANNON, P.; REINISCH, W. Interleukin 13 and its role in gut defence and in fl ammation. 1825. p. 1765-1773.

MAQSOOD, R.; STONE, T. W. The Gut-Brain Axis, BDNF, NMDA and CNS Disorders. Neurochem. Res., New York, v. 41, n. 11, p. 2819-2835, 2016.

MARQUES, F. Z.; MACKAY, C. R.; KAYE, D. M. Beyond gut feelings: how the gut microbiota regulates blood pressure. Nat. Rev. Cardiol., London, 2017.

MOLLOY, C. A. et al. Elevated cytokine levels in children with autism spectrum disorder. J. neuroimunnol., [s.I], v. 172, p. 198-205, 2006.

NAGASHIMA, K. et al. Identification of subepithelial mesenchymal cells that induce IgA and diversify gut microbiota. Nat. Immunol., New York, p. 1-10, 2017.

NEMANI, K. et al. Schizophrenia and the gut-brain axis. Progress in Neuro-Psychopharmacology and Biological Psychiatry, v. 56, p. 155160, 2015.

NEUFELD, K. M. et al. Reduced anxiety-like behavior and central neurochemical change in germ-free mice. Neurogastroenterol. Mot., Osney, v. 23, n. 3, p. 255-e119, mar. 2011.

NGUYEN, T. T. et al. Differences in gut microbiome composition between persons with chronic schizophrenia and healthy comparison subjects. Schizophr. Res., Amsterdam, n. xxxx, 2018.

O'MAHONY, S. M. et al. Serotonin, tryptophan metabolism and the brain-gut-microbiome axis. Behav. Brain Res., Amsterdam, v. 277, p. 32-48, 2015.

OKUBO, R. et al. PT US CR. [s.I.]: Elsevier, 2018.

OSOKINE, I.; ERLEBACHER, A. Inflammation and autism: from maternal gut to fetal brain. Trends in Molecular Medicine, Oxford, v. 23, n. 12, p. 1070-1071, 2017.

RIAL, S. A. et al. Gut microbiota and metabolic health: The potential beneficial effects of a medium chain triglyceride diet in obese individuals. Nutrients, [s.I], v. 8, n. 5, p. 1-19, 2016.

SAHA, S. et al. A Systematic Review of the Prevalence of Schizophrenia. PLoS Medicine, v. 2, n. 5, p. e141, maio 2005.

SANCTUARY, M. R. et al. Pilot study of probiotic / colostrum supplementation on gut function in children with autism and gastrointestinal symptoms. 2019. p. 1-30.

SCHROEDER, B. O.; BÄCKHED, F. Signals from the gut microbiota to distant organs in physiology and disease. Nat. Med., New Work, v. 22, n. 10, p. 1079-1089, 2016. 
SEVERANCE, E. G. et al. Gastroenterology issues in schizophrenia: why the gut matters. Curr. Psychiatry Rep., Philadelphia, v. 17, n. 5, 2015.

SEVERANCE, E. G. et al. Probiotic normalization of Candida albicans in schizophrenia: a randomized, placebo-controlled, longitudinal pilot study. Brain Behav. Immun., San Diego, v. 62, p. 41-45, 2017.

SHAABAN, S. Y. et al. The role of probiotics in children with autism spectrum disorder: A prospective, open-label study. Nutr. Neurosci, Amsterdam, v. 0, n. 0, p. 1-6, 2017.

SHERWIN, E. et al. May the Force Be With You: The Light and Dark Sides of the Microbiota-Gut-Brain Axis in Neuropsychiatry. CNS Drugs, v. 30, n. 11, p. 1019-1041, 2016.

STIO, M. et al. Vitamin D regulates the tight-junction protein expression in active ulcerative colitis. Scand. J. Gastroenterol., Oslo, v. 51, n. 10, p. 1193-1199, 2016.

TAN, J. et al. The role of short-chain fatty acids in health and disease. [s.l.]: Elsevier, 2014. v. 121.

TOMASIK, J. et al. Immunomodulatory effects of probiotic supplementation in schizophrenia patients : a randomized, placebo- controlled trial. Biomarker Insights, [s.I], v. 10, p. 47-54, 2015.

TOMOVA, A. et al. Physiology \& behavior gastrointestinal microbiota in children with autism in slovakia. Physiol. Behav., Elmsford, v. 138, p. 179-187, 2015.

VERDU, E. F.; GALIPEAU, H. J.; JABRI, B. Novel players in coeliac disease pathogenesis: role of the gut microbiota. Nature Publishing Group, [s.I], v. 12, p. 497-506, 2015.

WANG, Y. et al. Probiotics and fructo-oligosaccharide intervention modulate the microbiota-gut brain axis to improve autism spectrum reducing also the hyper-serotonergic state and the dopamine metabolism disorder. Pharmacol. Res., London, v. 157, p. 104784, 2020.

WATKINS, C. C.; ANDREWS, S. R. Clinical studies of neuroinflammatory mechanisms in schizophrenia. Schizophr. Res., Amsteradam, v. 176, n. 1, p. 14-22, 2016.

YANG, X. et al. More than 9,000,000 unique genes in human gut bacterial community: estimating gene numbers inside a human body. PLos ONE, San Francisco, v. 4, n. 6, p. e6074, June 2009.

Submetido em: $16 / 07 / 2020$

Aceito em: 14/12/2020 